\title{
Desenvolvimento e caracterização de geleia de laranja enriquecida com aveia
}

\author{
Camila Fernanda Dias de Oliveira ${ }^{1}$, Ellen Godinho Pinto ${ }^{2}$, Alessandra Cristina Tomé ${ }^{2}$, \\ Rosangela Coelho Quintana ${ }^{2}$, Bruna Ferreira Dias ${ }^{1}$

\footnotetext{
${ }^{1}$ Universidade Federal de Goiás - IFG, Campus Samambaia, Goiânia, Goiás, Brasil. E-mail: camilaferdias@gmail.com, brunaferreira142011@hotmail.com

${ }^{2}$ Instituto Federal Goiano - IF Goiano, Campus Morrinhos, Morrinhos, Goiás, Brasil. Email:alessandra.tome@ifgoiano.edu.br,
} \\ ellengodinho@hotmail.com, zanzaquintana@yahoo.com.br
}

Recebido: 15/04/2016; Aceito: 07/07/2016.

\section{RESUMO}

Este trabalho objetivou a caracterização físico-química e microbiológica da geleia de laranja enriquecida com aveia. As laranjas foram selecionadas manualmente, considerando-se ausência de manchas ou defeitos. As geleias foram elaboradas com a proporção de 50\%/50\% (polpa/sacarose) enriquecida com teor de aveia em três concentrações, sendo $1,5 \%, 3 \%$ e 4,5\%. Após o processamento das geleias foram avaliadas quanto ao teor de umidade, $\mathrm{pH}$, vitamina $\mathrm{C}$, sólidos solúveis totais e análise microbiológica. Diante dos resultados obtidos das análises físico-química, verificou-se que enriquecimento da geleia de laranja com aveia influenciou significativamente nos resultados de $\mathrm{pH}$ e sólidos solúveis totais ${ }^{\circ}$ Brix. Os resultados da análise microbiológica mostraram-se todas ausentes de coliformes a $45^{\circ} \mathrm{C}\left(\mathrm{NMP} \mathrm{g} \mathrm{g}^{-1}\right)$, apresentaram-se dentro dos parâmetros permitidos pela RDC $\mathrm{n}^{\circ} 12$, da ANVISA. Conclui-se que a laranja e a aveia têm influência direta nos resultados das composições físico-química e microbiológica. Portanto, a geleia pode ser realizada com boas perspectivas para a aplicação de frutas como a laranja e cereais como a aveia.

Palavras-chave: Análise físico-química, microbiológica, vitamina C.

\section{Development and characterization of jelly orange enriched with oats}

\begin{abstract}
This study aimed to physicochemical and microbiological characterization of oat enriched orange marmalade. The oranges were manually selected, considering the absence of stains or blemishes. The jams were prepared with the ratio of 50\%/50\% (pulp / sucrose) enriched with oat content in three concentrations being 1,5\%, 3\% and 4,5\%. After processing the jellies were evaluated for moisture content, $\mathrm{pH}$, vitamin $\mathrm{C}$, total soluble solids and microbiological analysis. Based on the results of physicochemical analyzes, it was found that enrichment of orange jelly with oatmeal significantly influence the results of $\mathrm{pH}$ and soluble solids totals ${ }^{\circ} \mathrm{Brix}$. The results of the microbiological analysis showed that all absentee coliforms at $45{ }^{\circ} \mathrm{C}$ (MPN g-1), presented themselves within the parameters allowed by RDC No. 12, ANVISA. It is concluded that orange and oatmeal has a direct influence on the results of the physicochemical and microbiological composition. Therefore, the jam can be performed with good prospects for the application of fruits such as orange and cereals such as oats.
\end{abstract}

Key words: physical-chemical, microbiological analysis, vitamin C. 


\section{Introdução}

Segundo a legislação brasileira, geleia é um produto preparado pelo cozimento de frutas inteiras ou em pedaços de variadas formas, da polpa ou do suco de frutas. Tais ingredientes devem ser misturados com açúcares, com ou sem adição de água, pectina, ácidos e outros ingredientes até atingir consistência gelatinosa adequada. Além disso, as geleias podem ser classificadas segundo percentual da fruta ou de seus ingredientes como, comum e extra. A comum, a proporção mínima de 40 partes de frutas para 60 partes de açúcar, enquanto a extra, proporção mínima de 40 partes de frutas para 60 partes de açúcar (BRASIL, 2005; ZANATTA et al. 2011).

A geleia de fruta é um produto de boa aceitação sensorial e com um alto valor agregado, possuindo um mercado que vem crescendo cada vez mais em busca de produtos processados com boa qualidade nutricional. Em 2010/2011, houve um acréscimo no volume exportado de $510,37 \%$, em produtos processados, essa abertura no comércio internacional é uma oportunidade de desenvolvimento de novos produtos (FERREIRA et al., 2011).

A laranja destaca-se não só pelo seu aroma e sabor agradável, como também pela rica composição nutricional, que apresenta teores elevados de vitamina $\mathrm{C}$ (ou ácido ascórbico - AA), e em sais minerais como, por exemplo, fósforo, cálcio e ferro. Deste modo, mostra-se com boa perspectiva de aplicação em geleias, pois o mercado consumidor vem aumentando com a procura por alimentos saudáveis (PASSOS et al. 2013; DIONIZIO et al., 2013).

Além da utilização de frutas para a elaboração de geleias, como diferencial neste trabalho, foi a incorporação da aveia. A aveia tem recebido grande atenção pela sociedade devido às suas características nutricionais, e principalmente devido ao seu teor e qualidade das fibras alimentares. A aveia reduz o colesterol sanguíneo, prevenindo doenças do coração e sendo considerado alimento funcional. A composição química e a qualidade nutricional da aveia são relativamente altas e superiores comparadas com os demais cereais (PIOVESANA et al., 2013).

Portanto, objetivou-se com este trabalho o desenvolvimento, caracterização físico-química $(\mathrm{pH}$, umidade, vitamina $\mathrm{C}$ e sólidos solúveis totais ${ }^{\circ} \mathrm{Brix}$ ) e microbiológica (coliformes totais) da geleia de laranja enriquecida com aveia.

\section{Material e Métodos}

As geleias foram elaboradas no laboratório de Agroindústria e as análises físico-química e microbiológica no laboratório de Microbiologia, no Instituto Federal Goiano Campus Morrinhos. A matéria- prima utilizada na elaboração das geleias de laranja enriquecidas com aveia foi adquirida no mercado local de Morrinhos-Goiás.

Os frutos foram cortados ao meio e despolpados com o auxílio de um espremedor de frutas. As geleias foram elaboradas com proporção de 50\%/50\%, (polpa/sacarose) enriquecida com teor de aveia em três concentrações, sendo 1,5\%, 3\% e 4,5\%. Essa concentração foi adaptada de Ferreira et al. (2011). Para isto, procedeu à cocção em panela de aço inoxidável, com agitação manual contínua até concentração final de sólidos solúveis de $65^{\circ}$ Brix, medido em refratômetro. As geleias foram envasadas em embalagens descartáveis com capacidade de 250 gramas.

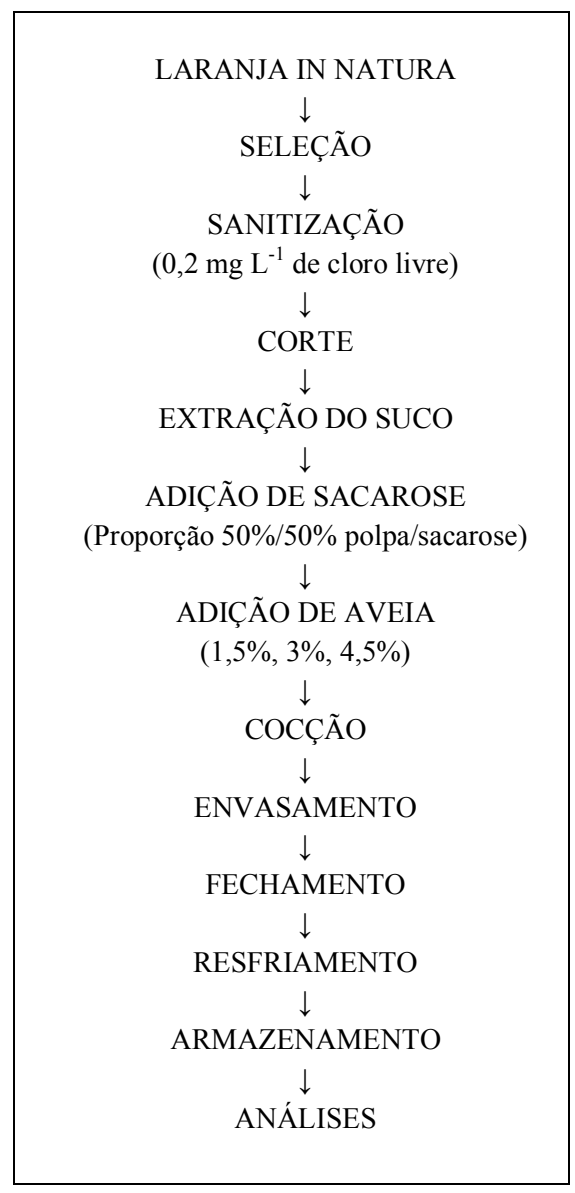

Figura 1. Fluxograma do processamento das geleias com diferentes concentrações de aveia.

As geleias foram analisadas quanto ao $\mathrm{pH}$ pelo método potenciométrico previamente calibrado com soluções padrão 4 e 7 , umidade pela perda de massa da amostra em estufa a $105 \pm 5^{\circ} \mathrm{C}$ cuja água e substâncias voláteis foram removidas, sólidos solúveis totais ( $\left.{ }^{\circ} \mathrm{Brix}\right)$ através de refratometometria e vitamina $\mathrm{C}$ quantificada pela oxidação do ácido ascórbico pelo iodato de potássio, todas realizadas em triplicata seguindo a metodologia do Instituto Adolfo Lutz (2004). 
Foi realizada a análise de coliformes totais a partir da técnica de número mais provável (NMP). Em que a realização do teste presuntivo foi retirada assepticamente $25 \mathrm{~g}$ da amostra e preparadas diluições sucessivas até $10^{-3}$. Foram pipetadas alíquotas de $\mathrm{mL}$ de cada diluição para uma série de três tubos de caldo LST (Lauril Sulfato Triptose) e incubados a $35{ }^{\circ} \mathrm{C}$ por 48 horas). De acordo com o Regulamento Técnico a avaliação microbiológica de geleias deverá conter pesquisa de coliformes a $45{ }^{\circ} \mathrm{C} / \mathrm{g}$. As análises microbiológicas foram realizadas em triplicata e seguiram os procedimentos descritos em (BRASIL, 2001).

Para as médias obtidas nos resultados das análises físico-químicas das três geleias, foram feitos os cálculos de desvio padrão. Foi utilizado o programa estatístico ASSISTAT aplicado o Teste de Tukey ao nível de 95\% de confiança.

\section{Resultados e Discussão}

Com relação aos resultados de umidade e vitamina $\mathrm{C}$, pode-se observar que as amostras provenientes das três concentrações de aveia não apresentaram diferenças significativas ao nível de $(\mathrm{p} \leq 0,05)$ significância. Portanto, a aveia não teve influência significativa nestes parâmetros. Porém, na análise de $\mathrm{pH}$ e sólidos solúveis totais a amostra de $1,5 \%$ de aveia se diferiu significativamente ao nível de $(\mathrm{p} \leq 0,05)$ significância. Este fato deve-se a concentração de aveia ser menor. De acordo com a legislação brasileira, é estabelecido um $\mathrm{pH}$ máximo de 3,4, o pH aqui apresentado teve um valor acima devido a presença de aveia que ter um $\mathrm{pH}$ em torno de 4,7, no entanto este valor de $\mathrm{pH}$ não impede sua comercialização, segundo Tsuchiya et al. (2009).

De acordo com Venâncio e Martins (2012), o pH das laranjas varia de 3,11 a 4,04, sendo que os valores obtidos nas amostras foram de 4,2 para a geleia de 1,5\% de aveia, 4,22 para a geleia de $3 \%$ de aveia e 4,23 para a geleia de 4,5\% de aveia. Segundo Albuquerque (1997) as geleias de frutas apresentam, em geral, $\mathrm{pH}$ e teor de sólidos solúveis em torno de 3,1 e $65{ }^{\circ}$ Brix, respectivamente.

O teor de sólidos solúveis encontrado foi de 62 ${ }^{\circ}$ Brix na geleia de $1,5 \%, 65{ }^{\circ}$ Brix na geleia de $3 \%, 66^{\circ}$ Brix na geleia de $4,5 \%$, ou seja, estando estes dentro dos padrões exigidos pela legislação brasileira, que deve permanecer em torno de $65^{\circ}$ Brix (TSUCHIYA et al. 2009). Logo, para o teor de sólidos solúveis totais era esperado que quanto menor a proporção de aveia menor o teor de sólidos solúveis totais, sendo observado neste trabalho. No entanto, os valores foram distantes daqueles encontrados por Foppa et al. (2009), ou seja, $79^{\circ}$ Brix em geleia de pêra Housui e $77^{\circ}$ Brix em geleia de pêra d'água.

Observando-se as geleias estudadas por Foppa et al. (2009) verificou-se que existe proximidade entre os valores de $\mathrm{pH}$ e vitamina $\mathrm{C}$, na qual, para a geleia de $1,5 \%$ de aveia possui respetivamente 4,20 e 13,98, na geleia de $3 \%$ de aveia 4,2 e 13,90 e na geleia de $4,5 \%$ de aveia 4,23 e 13,96.

Os valores encontrados para vitamina $\mathrm{C}$ estão abaixo dos encontrados por Gomes et al. (2013), ou seja, $31,37 \mathrm{mg} / 100 \mathrm{~g}$ de vitamina C. Isto provavelmente se deve a diferença de metodologia utilizada e/ou ao fato do produto ter sido elaborado em sistema de aquecimento sem controle da emissão de calor degradando assim a vitamina C (CORREIA et al. 2008).

A umidade encontrada nas amostras foram 34,63\% na geleia de $1,5 \%$ de aveia, $38,14 \%$ na geleia de $3 \%$ de aveia e $32,44 \%$ na geleia com $4,5 \%$ de aveia, valores próximos aos encontrados por Caetano et al. (2012), ou seja, 29,79 a $32,56 \%$ geleia elaborada com polpa e suco de acerola.

Os resultados das análises físico-química das geleias de laranja estão representados na Tabela 1.

Os resultados da análise microbiológica para os tratamentos com diferentes níveis de diluições das concentrações de geleia de laranja enriquecida com aveia podem ser visualizados na Tabela 2 .

Tabela 1. Caracterização físico-química da geleia de laranja enriquecida com aveia.

\begin{tabular}{lccc}
\hline Determinações físico-química & $\begin{array}{c}\text { Geleia de laranja com } \\
1,5 \% \text { de aveia }\end{array}$ & $\begin{array}{c}\text { Geleia de laranja com } \\
3 \% \text { de aveia }\end{array}$ & $\begin{array}{c}\text { Geleia de laranja com } \\
4,5 \% \text { de aveia }\end{array}$ \\
\hline $\mathrm{pH}$ & $4,2 \pm 0^{\mathrm{a}}$ & $4,22 \pm 0,1^{\mathrm{b}}$ & $4,23 \pm 0,05^{\mathrm{b}}$ \\
Sólidos Solúveis ( ${ }^{\circ}$ Brix) & $62^{\mathrm{a}}$ & $65^{\mathrm{b}}$ & $66^{\mathrm{b}}$ \\
Umidade (\%) & $34,63 \pm 2,77^{\mathrm{a}}$ & $38,14 \pm 1,05^{\mathrm{a}}$ & $32,44 \pm 0,41^{\mathrm{a}}$ \\
Vitamina C (mg/100g de ácido ascórbico) & $13,98 \pm 0,08^{\mathrm{a}}$ & $13,90 \pm 0,06^{\mathrm{a}}$ & $13,96 \pm 0,04^{\mathrm{a}}$ \\
\hline
\end{tabular}

Médias seguidas pela mesma letra na linha não difere estatisticamente entre si, pelo teste Tukey, a nível de $(\mathrm{p} \leq 0,05)$ de significância. * Médias estão acompanhadas do desvio padrão. 
Tabela 2. Resultados médios das análises microbiológicas nos tratamentos formulados com diferentes níveis de concentração de geleia de laranja enriquecida com aveia.

\begin{tabular}{lc}
\hline $\begin{array}{c}\text { Tratamentos com diferentes } \\
\text { concentrações de geleia }\end{array}$ & $\begin{array}{c}\text { Coliformes a } 45^{\circ} \mathrm{C} \\
\left(\mathrm{NMP} \mathrm{g}^{-1}\right)\end{array}$ \\
\hline Concentração $10^{-1}(\mathrm{a})$ & Ausente \\
Concentração $10^{-2}(\mathrm{~b})$ & Ausente \\
Concentração $10^{-3}(\mathrm{c})$ & Ausente \\
Concentração $10^{-1}(\mathrm{a})$ & Ausente \\
Concentração $10^{-2}(\mathrm{~b})$ & Ausente \\
Concentração $10^{-3}(\mathrm{c})$ & Ausente \\
Concentração $10^{-1}(\mathrm{a})$ & Ausente \\
Concentração $10^{-2}(\mathrm{~b})$ & Ausente \\
Concentração $10^{-3}(\mathrm{c})$ & Ausente \\
\hline *NMP g-1 = número mais provável por grama de amostra \\
(a)= Geleia com $1,5 \%$ de aveia \\
(b)= Geleia com $3,0 \%$ de aveia \\
(c) = Geleia com $4,5 \%$ de aveia
\end{tabular}

Os resultados da análise microbiológica mostraramse todas ausentes de coliformes a $45{ }^{\circ} \mathrm{C}\left(\mathrm{NMP} \mathrm{g}^{-1}\right)$, apresentaram-se dentro dos parâmetros permitidos pela RDC $n^{\circ} 12$, da ANVISA segundo (BRASIL, 2001), que determina para as geleias de frutas a submissão do padrão máximo de $102 \mathrm{NMP} \mathrm{g}^{-1}$ para coliformes a $45^{\circ} \mathrm{C}$. Ou seja, foram utilizadas as boas práticas de fabricação, abrangendo desde as matérias-primas até o produto final, de forma a garantir a segurança e integridade do consumidor.

\section{Conclusões}

Conclui-se que a laranja e a aveia têm influência direta nos resultados das composições físico-química e microbiológica. Portanto, a geleia pode ser realizada com boas perspectivas para a aplicação de frutas como a laranja e cereais como a aveia.

\section{Referências Bibliográficas}

ALBUQUERQUE, J. P. Fatores que influem no processamento de geleias de frutas. Boletim SBCTA, Campinas-SP, v. 31, n. 1, p. 62-67, 1997.

BRASIL, Resolução RDC n ${ }^{\circ} 12$, de 02/01/2001. Estabelece regulamento técnico sobre os padrões microbiológicos para alimentos. Disponível: <http://www.anvisa.org.br> Acesso em 24 de março de 2016.

BRASIL. Ministério da Saúde. Agência Nacional de Vigilância Sanitária. Resolução RDC $\mathbf{n}^{\circ}$ 272, de 22 de setembro de 2005. Aprova o regulamento Técnico para produtos vegetais, produtos de frutas e cogumelos comestíveis. Diário Oficial [da República Federativa do Brasil], Brasília, DF, 23 de setembro de 2005.

CAETANO, P. K.; DAIUTO, E. R.; VIEITES, R. L. Característica físico-química e sensorial de geleia elaborada com polpa e suco de acerola. Brazilian Journal of food Technology, Campinas-SP, v. 15, n. 3, p. 191-197, 2012.
CORREIA, L. F. M.; FARAONI, A. S.; PINHEIROSANT'ANA, H. M. Efeitos do processamento industrial de alimentos sobre a estabilidade de vitaminas. Alimentos e Nutrição, Araraquara-SP, v. 19, n. 1, p. 83-95, 2008.

DIONIZIO, A. D. S.; BATISTA, D. V. S.; CARDOSO, R. L.; CEDRAZ, K. A.; SANTOS, D. B. D. Elaboração e caracterização físico-químicas e sensorial de geleia de jaca com laranja. Enciclopédia Biosfera, Goiânia-GO, v. 9, n. 17, p. 10-17, 2013

FERREIRA, R. M. A.; AROUCHA, E. M. M.; GÓIS, A. V., SILVA, K. D.; SOUSA, C. M. G. S. Qualidade sensorial de geleia mista de melancia e tamarindo. Revista Caatinga. Mossoró-RN, v. 24, n. 2, p. 202-206, 2011.

FOPPA, T.; TSUZUKI, M. M.; SANTOS, C. E. S. Caracterização físico-química da geleia de pera elaborada através de duas cultivares diferentes: Pera D’Água (Pyrus communis L.) e housui (Pyrus pyrifolia Nakai). Revista Brasileira de Produtos Agroindustriais. Campina GrandePB, v. 11, n. 1, p. 21-25, 2009.

GOMES, R. B.; SANTOS, M. B.; CARDOSO, R. L.; TAVARES, J. T. Q.; CUNHA, D. S. Elaboração e avaliação físico-química e sensorial de geleia de maracujá com cenoura. Enciclopédia Biosfera, Goiânia-GO, v. 9, n. 16, p. 2, 2013.

INSTITUTO ADOLFO LUTZ. Normas Analíticas do Instituto Adolfo Lutz. Métodos químicos e físicos para análise de alimentos. v. 1, 4. ed. São Paulo-SP: Inst. Adolfo Lutz, 2004.

PASSOS, F. R.; CRUZ, R. G.; SANTOS, M. S.; FERNANDES, R. V. B. Avaliação físico-química e sensorial de licores mistos de cenoura com laranja e com maracujá. Revista Brasileira de Produtos Agroindustriais, Campina Grande-PB, v. 15, n. 3, p. 211-218. 2013.

PIOVESANA, A.; MARIA, M. B.; MARIA, K. V. Elaboração e aceitabilidade de biscoitos enriquecidos com aveia e farinha de bagaço de uva. Brazilian Journal of Food Technology, Campinas-SP, v. 16, n. 1, p. 68-72, 2013.

TSUCHIYA, A. C.; SILVA, A. G. M.; SOUZA, M.; SCHMIDT, C. A. P. Caracterização físico-química, microbiológica e sensorial de geleia de tomate. Revista Brasileira de Produtos Agroindustriais, Campina GrandePB, v. 11, n. 2, p. 165-170, 2009

VENÂNCIO, A. A.; MARTINS, O. A. Análise química de diferentes marcas de néctares e Suco de laranja comercializada na cidade de Cerqueira César. Revista Eletrônica de Educação e Ciência, São Paulo-SP, v. 02, n. 03, p. 45-50, 2012.

ZANATTA, C. L.; SCHLABITZ, C.; ETHUR, E. M. Avaliação físico-química e microbiológica de farinhas obtidas a partir de vegetais não conformes à comercialização. Alimentos e Nutrição, Araraquara-SP, v. 21, n. 3, p. 459-468, 2011. 